Article

\title{
Development of Robust Chitosan-Silica Class II Hybrid Coatings with Antimicrobial Properties for Titanium Implants
}

\author{
Zach Gouveia ${ }^{1}$, Hiran Perinpanayagam ${ }^{2}$ (D) and Jesse Zhu ${ }^{1,3, *}$ \\ 1 School of Biomedical Engineering, University of Western Ontario, London, ON N6A 3K7, Canada; \\ zgouveia@uwo.ca \\ 2 Schulich School of Medicine and Dentistry, University of Western Ontario, London, ON N6A 5C1, Canada; \\ hperinpa@uwo.ca \\ 3 Department of Chemical and Biochemical Engineering, University of Western Ontario, \\ London, ON N6A 3K7, Canada \\ * Correspondence: jzhu@uwo.ca
}

Received: 6 May 2020; Accepted: 28 May 2020; Published: 30 May 2020

check for updates

\begin{abstract}
The purpose of this study was to develop robust class II organic-inorganic films as antibacterial coatings on titanium alloy (Ti6Al4V) implants. Coating materials were prepared from organic chitosan (20-80 wt.\%) coupled by 3-glycydoxytrimethoxysilane (GPTMS) with inorganic tetraethoxysilane (TEOS). These hybrid networks were imbedded with antimicrobial silver nanoparticles (AgNPs) and coated onto polished and acid-etched Ti6Al4V substrates. Magic-angle spinning nuclear magnetic resonance (13CMAS-NMR), attenuated total reflectance Fourier-transform infrared spectroscopy (ATR-FTIR) and the ninhydrin assay, confirmed the presence and degree of covalent crosslinking (91\%) between chitosan and GPTMS. Scanning electron microscopy (SEM) and energy-dispersive X-ray spectroscopy (EDS) identified surface roughness and microtopography on thin films and confirmed homogeneous distribution of elements throughout the coating. Cross-hatch and tensile adhesion testing demonstrated the robustness and adherence (15-20 MPa) of hybrid coatings to acid-etched titanium substrates. Staphylococcus aureus and Escherichia coli cultures and their biofilm formation were inhibited by all hybrid coatings. Antibacterial effects increased markedly for coatings loaded with AgNPs and appeared to increase with chitosan content in biofilm assays. These results are promising in the development of class II hybrid materials as robust and highly adherent antibacterial films on Ti6Al4V implants.
\end{abstract}

Keywords: antibacterial coating; chitosan; silver nanoparticles; sol-gel; thin films; titanium implants

\section{Introduction}

Titanium and its alloys have been the material of choice for biomedical implants over the past half century. Their low specific weight, high strength to weight ratio and resistance to corrosion are features that make titanium the ideal bulk material for numerous clinical applications [1]. These include orthopedic and dental implants where their resistance to chipping and capacity to endure repetitive high loading conditions are an advantage over non-metallic substrates. Furthermore, the titanium dioxide layer that forms on their surfaces is highly inert and biocompatible to the cells and extracellular matrix of surrounding tissues.

However, the bio-inertia of titanium surfaces is accompanied by a lack of any significant antimicrobial properties. While implanted titanium materials are well received by the osseous and connective tissues of their host, microbial contamination of their surfaces and the surgical site can often lead to sustained infections and unfavorable patient outcomes. These implant-associated infections are currently a major cause of orthopedic and dental implant failures. Post-operative infections associated 
with biomaterial implantation range from $2-5 \%$ for orthopedic procedures and $4-11.5 \%$ for dental and oral surgeries [2-4]. These infections are often extremely resistant to systemic antibiotics and persist until the implant has been surgically retrieved.

The persistence of implant-associated infections is likely due to the presence of polymicrobial biofilms that have formed on implant surfaces. These biofilms contain bacteria that are encased within a bacterial-excreted polysaccharide matrix, which is highly adherent to biomaterial surfaces and largely resistant to the external environment. Accordingly, the bacteria within biofilms may be up to 1000 times more resistant to antibiotics than bacteria that are suspended in a planktonic state [3,5].

Therefore, research has now been directed toward the modification of implant surfaces to prevent initial bacterial adhesion and subsequent biofilm formation. Most antimicrobial strategies have relied on either static antimicrobial activity from direct or indirect surface modifications or they have implemented release-based antimicrobial action using biocides imbedded within material surfaces.

Static antimicrobial strategies involve modifications to implant surface properties which can alter their surface roughness, hydrophilicity and/or surface functional groups [6-8]. Therefore, such intensive surface modifications can lack selectivity for biomedical applications and may inadvertently reduce favorable surface interactions with mammalian cells. These cellular responses are necessary for cell attachment and adequate osseointegration with surrounding tissues [9]. Furthermore, while static antimicrobial factors may inhibit or retard initial bacterial adhesion and proliferation, they become ineffective once biofilms become established on biomaterial surfaces.

In contrast, release-based antimicrobial strategies typically employ a coating system that enables the release of biocidal components such as antibiotics, cationic molecules or metallic compounds [10-13]. Systems that employ release-based antimicrobial strategies often involve an initial burst release of the imbedded biocidal agents that have short-term effects, which are followed by a subsequent diminution of activity. Additionally, for release-based systems the choice of an antibiotic as a biocidal agent may be contraindicated by the rise in antibiotic-resistant infections from resistant bacterial strains [14].

Therefore, recent interest has focused on the utilization of metallic nanoparticles as antimicrobial agents, due to their broad-spectrum effects $[15,16]$. Among these, silver nanoparticles (AgNPs) have garnered significant interest due to their limited cytotoxicity, ease of synthesis, low minimum inhibitory concentrations for many pathogenic bacteria and their antimicrobial efficacies in both static and release-based applications [17-19]. AgNPs provide antibacterial efficacy through both the release of silver ions $\left(\mathrm{Ag}^{+}\right)$and through the direct action of metallic $\mathrm{AgNPs}\left(\mathrm{Ag}^{0}\right)$. The $\mathrm{Ag}^{+}$provide antibacterial effects by permeating cell walls, damaging proteins and membranes and causing oxidative stress [20]. The antibacterial action of $\mathrm{Ag}^{0}$ is by a similar permeation-based toxicity, as well as through cell surface attachment and disturbances to the permeability and metabolism of bacterial cells [21,22].

Currently, surface modifications to titanium implants are limited commercially to surface treatments (physical roughening, anodizing, chemical etching, etc.) and inorganic ceramic coatings that typically incorporate hydroxyapatite (HAp) as a bioactive layer. However, the application of such ceramic coatings has numerous disadvantages such as slow processing (biomimetism), high temperature application (plasma spraying) and overly thick or brittle film deposition, which limit their ability to be loaded with process sensitive antimicrobials [23-25]. Therefore, there was significant interest in using alternative coating materials containing organic components, which could improve the material properties and processability of coating materials while retaining an adequate level of bioactivity within tissues.

One organic material being considered for coating applications is chitosan, which is a naturally occurring polycationic polymer derived from the shells of crustaceans. Chitosan is both biocompatible, biodegradable and has antibacterial effects. Due to these unique properties, chitosan has already found use in multiple biomedical applications that include drug delivery [26-28], tissue engineering [29-31], ophthalmology [32-34] and as medical device coatings [35-37]. However, chitosan alone has a propensity to degrade and has weak mechanical properties in vivo that would make it a poor choice as a coating for implantable titanium materials. 
Therefore, the development of class II organic-inorganic hybrid materials that retain the biologic benefits of polymers such as chitosan, while enhancing their physical properties, has been proposed [38-40]. By covalently coupling biopolymers to inorganic precursors, hybrid materials could be developed that retain their biocompatibility and have improved mechanical properties. For example, gelatin has been utilized as the organic component in a class II hybrid framework with silica, to develop highly porous scaffolds for bony tissue applications with tunable mechanical and dissolution properties [41]. Similarly, chitosan has been shown to be an appropriate biopolymer for covalent coupling with silica networks that are otherwise too brittle [42-45]. Coupling with inorganic silica networks, in these cases, significantly improves the mechanical properties of chitosan alone for applications as biomaterials. Similar studies have used chitosan as a primary organic network modifier and sole antimicrobial agent in the development of coatings for titanium implant materials [46,47]. These studies have shown that such materials could promote bone forming ability and provide an antimicrobial effect against clinically relevant pathogens. This study evaluated the robustness of these materials and investigated the inclusion of AgNPs into the coating network to improve antimicrobial efficacy against both static and planktonic pathogens.

Therefore, the purpose of this research was to develop robust and functional chitosan-silica coatings for titanium implants. The objective was to develop robust chitosan-silica class II hybrid coatings that could be loaded with AgNPs for manifest antibacterial properties.

\section{Materials and Methods}

\subsection{Synthesis of Coating Materials}

All chemicals involved in the preparation of coating materials were purchased as laboratory grade reagents from Sigma Aldrich (St. Louis, MO, USA), unless otherwise specified. There were four formulations of chitosan-silica hybrid coating materials prepared (Table 1). Their composition and preparation were identical, except for their organic content that varied from $20 \%$ to $80 \%$ by weight. The variation in organic content was achieved by modifying the ratio of tetraethoxysilane (TEOS) to chitosan coupled with 3-glycidyloxypropyltrimethoxysilane (Ch-GPTMS).

Table 1. Composition of hybrid coatings.

\begin{tabular}{|c|c|c|c|c|c|c|c|c|}
\hline \multirow{2}{*}{ Components } & \multicolumn{2}{|c|}{$80 \%$ Organic Blends } & \multicolumn{2}{|c|}{$60 \%$ Organic Blends } & \multicolumn{2}{|c|}{$40 \%$ Organic Blends } & \multicolumn{2}{|c|}{$20 \%$ Organic Blends } \\
\hline & $\begin{array}{l}80 \% \\
\mathrm{ChSi}\end{array}$ & $\begin{array}{c}80 \% \\
\text { ChSi-nAg }\end{array}$ & $\begin{array}{l}60 \% \\
\mathrm{ChSi}\end{array}$ & $\begin{array}{c}60 \% \\
\text { ChSi-nAg }\end{array}$ & $\begin{array}{l}40 \% \\
\mathrm{ChSi}\end{array}$ & $\begin{array}{c}40 \% \\
\text { ChSi-nAg }\end{array}$ & $\begin{array}{l}20 \% \\
\mathrm{ChSi}\end{array}$ & $\begin{array}{c}20 \% \\
\text { ChSi-nAg }\end{array}$ \\
\hline Ch-GPTMS ${ }^{\text {a }}$ & 80 & 80 & 60 & 60 & 40 & 40 & 20 & 20 \\
\hline TEOS $\mathrm{b}$ & 20 & 20 & 40 & 40 & 60 & 60 & 80 & 80 \\
\hline $\mathrm{AgNPs}^{c}$ & - & 0.023 & - & 0.023 & - & 0.023 & - & 0.023 \\
\hline
\end{tabular}

${ }^{a}$ Chitosan coupled with 3-glycidyloxypropyltrimethoxysilane (network wt.\%); ${ }^{b}$ tetraethoxysilane (network wt.\%);

${ }^{c}$ silver nanoparticles (total coating wt.\%)

A coupling reaction between chitosan and GPTMS was initiated as previously described [42,45]. Briefly, chitosan ( $200 \mathrm{kDa}, 82 \% \mathrm{DDA})$ was dissolved in an acidic solution $(\mathrm{HCl}, \mathrm{pH} 4.0)$ to a concentration of $18 \mathrm{mg} / \mathrm{mL}$. This chitosan solution was strained through a cotton filter and then GPTMS was added at a 1:1 molar ratio of solubilized chitosan to GPTMS and left to couple over a period of $24 \mathrm{~h}$ at room temperature. Following coupling, an appropriate amount of hydrolyzed TEOS ( $\mathrm{pH} 4.0$ ) was added to the Ch-GPTMS solution to yield hybrids of varying organic content (20,40, 60 and $80 \mathrm{wt} . \%)$. The inorganic component of the hybrid material was controlled independently using TEOS. After the addition of an appropriate amount of TEOS as the inorganic component in the hybrid material, duplicate preparations of each coating material were loaded with AgNPs $(0.023 \mathrm{wt} . \%)$ and agitated maximally for $1 \mathrm{~h}$.

The AgNPs were synthesized by a chemical reduction method, as previously described [48-50]. Initially, a solution of $\mathrm{NaBH}_{4}\left(2.0 \times 10^{-3} \mathrm{M}\right)$ was prepared in double distilled water and chilled in an ice bath for $15 \mathrm{~min}$. Concurrently, a solution of $\mathrm{AgNO}_{3}\left(2.0 \times 10^{-3} \mathrm{M}\right)$ was prepared in double distilled 
water. While the solution of $\mathrm{NaBH}_{4}$ was stirred vigorously, the solution of $\mathrm{AgNO}_{3}$ was added dropwise with $\mathrm{NaBH}_{4}$ being in excess $\left(\mathrm{NaBH}_{4}: \mathrm{AgNO}_{3} 6: 1 \mathrm{v} / \mathrm{v}\right)$. Following the addition of $\mathrm{AgNO}_{3}$, stirring was stopped and the AgNP colloid was stabilized with an appropriate amount of polyvinylpyrrolidone (0.3 wt.\% PVP) solution. The PVP stabilized AgNP solutions were then subjected to repeated cycles of ultracentrifugation and freeze-drying to collect concentrated AgNPs.

The synthesized AgNPs were examined by transmission electron microscopy (TEM). Nickel grids (400 mesh) were dipped in aqueous suspensions of AgNPs and allowed to air-dry. Analysis was performed using a Philips 420 TEM at an accelerating voltage of $80 \mathrm{kV}$ equipped with an AMT 4000 digital imaging system.

\subsection{Deposition of Hybrid Coatings}

Commercially available titanium alloy (Ti6Al4V) discs $(9 \times 9 \times 2 \mathrm{~mm})$ were polished with silicon carbide study up to 1200 grit, then rinsed with acetone and washed by ultrasonication in deionized water. Some discs were then immersed in a solution of $\mathrm{HCl}$ and $\mathrm{H}_{2} \mathrm{SO}_{4}$ in double distilled water $(2: 2: 1 \mathrm{v} / \mathrm{v})$ at $65{ }^{\circ} \mathrm{C}$ for $20 \mathrm{~min}$. Following this etching process, these discs were neutralized with a $\mathrm{NaHCO}_{3}$ solution $(0.5 \mathrm{M})$, washed by ultrasonication in deionized water and ethanol and dried at $40^{\circ} \mathrm{C}$.

The polished and acid-etched Ti6Al4V discs were used as substrates for the application of chitosan-silica class II hybrid coatings in a standard dip-coating protocol [51]. Briefly, the discs were immersed in freshly prepared chitosan-silica sol using a dip and withdrawal speed of $100 \mathrm{~mm} / \mathrm{min}$. Following dip coating, the discs were dried in a vacuum oven at $80^{\circ} \mathrm{C}$ for $3 \mathrm{~h}$ and then stored at room temperature.

\subsection{Characterization of Coating Surfaces}

The hybrid coating surfaces were carefully analyzed for their chemical structure, composition and microtopographies. The presence of covalent coupling between chitosan and GPTMS was identified by solid-state nuclear magnetic resonance (NMR). ${ }^{13} \mathrm{C}$ Magic-angle spinning (MAS) NMR spectra were acquired at natural abundance on a 14.1 T Inova I600 NMR Spectrometer (Varian Inc., Palo Alto, CA, USA) operating at $79.4 \mathrm{MHz}$. Hybrid coating samples were spun at $13 \mathrm{kHz}$ using a $3.2 \mathrm{~mm}$ MAS HXY probe. In addition, the degree of covalent coupling was measured with a ninhydrin assay as follows [52,53]. Briefly, a ninhydrin solution was added to solid suspensions of the coating samples at $80^{\circ} \mathrm{C}$ for $20 \mathrm{~min}$. Solid suspensions were prepared by grinding dried coating materials with a mortar and pestle and suspending the fine powder in double distilled water. The absorbance of prepared suspensions was measured at $570 \mathrm{~nm}$ using a spectrophotometer (G1103A, Agilent Technologies, Santa Barbara, CA, USA) and compared to a standard curve prepared from the chitosan batch used in this study. Using the standard curve, the percentage of free (uncoupled) amino groups present in the coating samples was calculated.

The surface morphologies and microtopographies of the hybrid coatings were examined by scanning electron microscopy (SEM), using a Hitachi SU8230 Regulus Ultra High-Resolution Field Emission SEM (Hitachi, Tokyo, Japan). The coated Ti6Al4V discs were secured to metal stubs with carbon tape and sputter coated with $10 \mathrm{~nm}$ gold nanoparticles prior to analysis. Additionally, elemental distribution maps of the coating surfaces were obtained by energy-dispersive $X$-ray spectroscopy (EDX) using a Bruker X-Flash FQ5060 Annular Quad EDX detector (Brunker, Billerica, MA, USA).

The chemical structure of the coatings and the presence of key functional groups were analyzed using attenuated total reflectance Fourier transform infrared spectroscopy (ATR-FTIR). Hybrid coating samples were analyzed using a Bruker Tensor II system with a Platinum ATR (unit A225) equipped with a $2 \times 2 \mathrm{~mm}$ diamond crystal (Brunker, Billerica, MA, USA). Spectra were acquired in the range of $4000-400 \mathrm{~cm}^{-1}$, at a resolution of $4 \mathrm{~cm}^{-1}$ and taken as an average of 32 scans. All spectra were analyzed using OPUS spectroscopy software. 


\subsection{Evaluation of Mechanical Properties}

The mechanical properties of the hybrid coatings and their interface with underlying titanium substrates were carefully evaluated. Their surface energies were analyzed by measuring the water contact angle for double distilled water. The water contact angles were measured by the DataPhysics OCA 30 (DataPhysics, Filderstadt, Germany) using the sessile drop method. Drop volume was maintained at $10 \mu \mathrm{L}$ and replicate $(n=5)$ measurements were obtained.

Overall, adhesion of the hybrid coatings to their titanium substrates was evaluated qualitatively using an abbreviated cross hatch adhesion protocol (ASTM D3359 [54]). Briefly, the coatings were scored using a cross hatch cutter (Elcometer, Manchester, United Kingdom) with standardized blade spacing $(11 \times 1 \mathrm{~mm})$. There were two perpendicular cuts $(20 \mathrm{~mm})$ that were made with a steady motion and force to penetrate the coating layer and create a lattice pattern. ASTM standard tape was then placed over the center of the grid, smoothened with a pencil eraser and then withdrawn in a steady motion at an angle of $180^{\circ}$ from the substrate. Resultant defects in the coating layer were examined using a brightfield microscope at a magnification of 50× (Mitutoyo, Kanagawa, Japan).

Quantitative assessments of the coatings' adhesion to titanium substrates and risks of delamination were obtained through a tensile adhesion protocol as follows (Figure 1) [55]. The coated Ti6Al4V discs were fixed to aluminum dolly specimens with T-88 epoxy resin (System Three Resins, Inc., Lacey, WA, USA). The affixed samples were secured to a tension adapter in an Adelaide TCC universal testing machine (Adelaide Testing Machines, Toronto, ON, Canada), and forced apart at a speed of $3 \mathrm{~mm} / \mathrm{min}$. Each coating and treated titanium substrate were tested in triplicate $(n=3)$. Following separation, the site of delamination was carefully examined, with the coating adhesive strength calculated as:

$$
\text { Adhesive Stength }(\mathrm{MPa})=\frac{\text { Load at Failure }(\mathrm{N})}{\text { Coated Area }\left(\mathrm{m}^{2}\right)}
$$

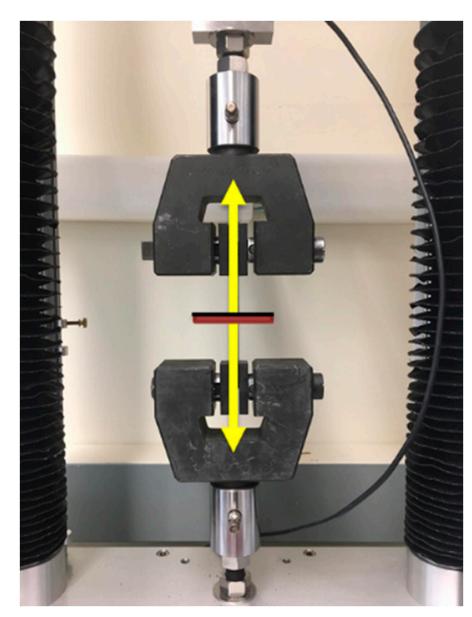

Figure 1. Adhesive tensile testing of hybrid coatings on titanium (Ti6Al4V) substrates. The coating (black line) and Ti6Al4V substrate (red line) are forced apart (yellow arrows) in an Adelaide TCC universal testing machine.

\subsection{Evaluation of Antimicrobial Properties}

The antimicrobial properties of the hybrid coatings were evaluated against common Gram-positive and -negative bacterial pathogens. Their antimicrobial efficacies were assessed quantitatively against Escherichia coli (Gram-negative, ATCC ${ }^{\circledR}$ 25922) and Staphylococcus aureus (Gram-positive, ATCC ${ }^{\circledR} 25923$ ) suspended in planktonic bacterial cultures and on their formation of adherent biofilms. Separate E. coli and S. aureus monocultures suspended in Luria Bertani (LB) medium were prepared from inoculum. 
The coated discs were disinfected and sterilized in preparation for bacterial cultures. They were rinsed twice with ethanol $(70 \% v / v)$, washed thrice with phosphate buffered saline (PBS), then placed in a tissue culture hood and exposed to UV light for 30 minutes to ensure sterility. Replicate coated discs ( $n=3 /$ coating) were submerged in each bacterial suspension of $10^{5} \mathrm{CFU} / \mathrm{mL}$ and incubated at $37^{\circ} \mathrm{C}$ under aerobic conditions. At predetermined times $(1,2,4, \ldots, 24 \mathrm{~h})$, samples of the bacterial suspension were withdrawn and their absorbance $\left(\mathrm{OD}_{600}\right)$ measured using a spectrophotometer (Agilent Technologies, Santa Barbara, CA, USA). Viable cells from the samples of bacterial suspension were counted by serial dilution and the spread plate method using $100 \times 15 \mathrm{~mm}$ LB Agar plates.

Additional sterile coated discs ( $n=3 /$ coating) were submerged in each bacterial suspension of $10^{5} \mathrm{CFU} / \mathrm{mL}$ and incubated at $37^{\circ} \mathrm{C}$ under aerobic conditions for a period of $24 \mathrm{~h}$. Following incubation, the coated discs were gently rinsed thrice with sterile PBS, transferred to sterile culture tubes containing $2 \mathrm{~mL}$ of fresh LB medium and subjected to ultrasonication for $5 \mathrm{~min}$. Viable bacteria were harvested from the sonicated samples and counted by serial dilution and the spread plate method using $100 \times 15 \mathrm{~mm} \mathrm{LB}$ Agar plates. The inhibition of bacterial biofilm formation was calculated with $\mathrm{CFU}_{\text {control }}$ representing colonies on uncoated control (Ti6Al4V) surfaces and $\mathrm{CFU}_{\text {coating }}$ being the colonies on each coating as:

$$
\text { Bacterial Inhibition }(\%)=\frac{\mathrm{CFU}_{\text {Contol }}-\mathrm{CFU}_{\text {Coating }}}{\mathrm{CFU}_{\text {Control }}} \times 100
$$

\subsection{Statistical Analysis}

The data in this study were analyzed using GraphPad Prism software (V 6.01). All data are expressed as mean \pm standard deviation. One-way ANOVA analyses were used to make comparisons among multiple groups. Group differences were specified using Tukey's post hoc tests with the differences considered statistically significant when $p<0.05$.

\section{Results and Discussion}

\subsection{Characterization of Coating Materials}

The first step in this research was to successfully synthesize class II hybrid coating materials. Class II hybrids have been shown to display synergistic properties that complement the advantages of both organic and inorganic polymers [56]. In this study, class II hybrid materials were developed using chitosan as an organic polymer component, GPTMS as a silane coupling agent and TEOS as an independent inorganic network agent. Initially, covalent coupling occurred between the epoxide functional group of GPTMS and the primary amine group of chitosan (Figure 2A). Concurrently, the acidic conditions of the reaction catalyzed the hydrolysis of ethoxysilane bonds to form $\mathrm{Si}-\mathrm{OH}$ pendants. Following coupling, pre-hydrolyzed TEOS was added to the solution of functionalized chitosan, and polycondensation of the network proceeded to occur through the formation of $\mathrm{Si}-\mathrm{O}-\mathrm{Si}$ linkages. After the addition of hydrolyzed TEOS, some of the materials had aqueous suspensions of AgNPs added to their blend to create antimicrobial coatings.

To verify that these coating materials were indeed class II hybrids, it was essential to confirm that there was covalent coupling between the organic and inorganic components. In this study, the coupling of chitosan using its primary amine functionality to GPTMS was evaluated, because the epoxide functional group of GPTMS is known to form covalent bonds with nucleophilic functional groups such as amines under acidic conditions [57]. To observe these reactions between GPTMS and chitosan, ${ }^{13} \mathrm{C}$ MAS-NMR spectroscopy was used. The coupling reaction could be followed by identifying the peak assignments previously described (Figure 3) [43]. The ${ }^{13} \mathrm{C}$ resonance labeled ' 6 ' (associated with the carbon in the epoxide ring) at $\delta \sim 47 \mathrm{ppm}$, showed that some of the epoxide rings of GPTMS had been opened by a nucleophilic attack of the primary amine of chitosan to form a secondary amine. There were no other reactions between chitosan and GPTMS identified, which indicated that the coupling occurred exclusively between the primary amine of chitosan and the epoxide of GPTMS. 
Indeed, these findings are consistent with what has been reported by others for the coupling of chitosan and GPTMS under similar conditions [43,45].

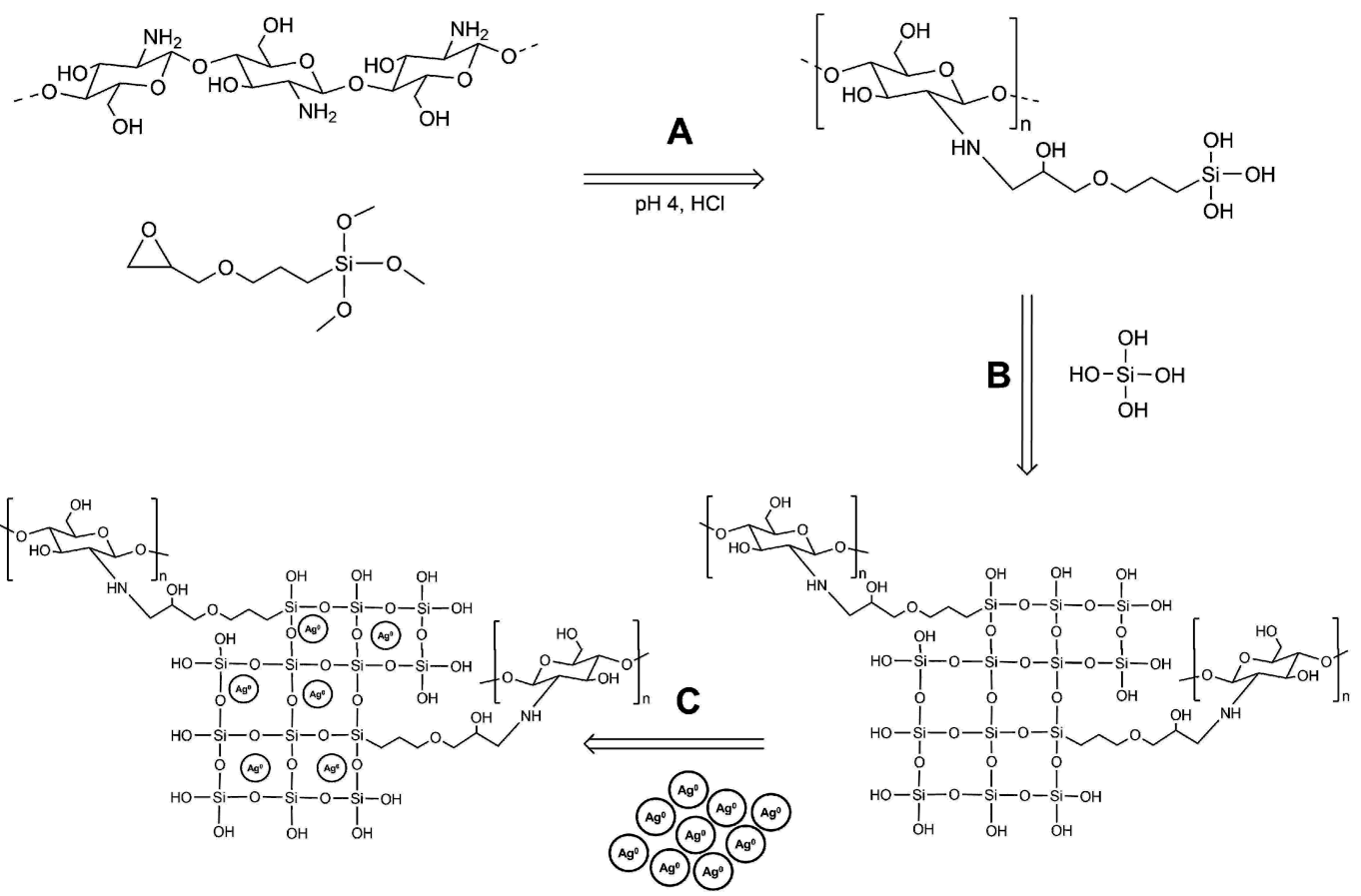

Figure 2. Chemical synthesis of chitosan-silica Class II hybrids and imbedding of silver nanoparticles (AgNPs). (A) Coupling of chitosan and 3-glycidyloxypropyltrimethoxysilane (GPTMS) in mildly acidic conditions; (B) polycondensation of coupled chitosan and hydrolyzed tetraethoxysilane (TEOS); (C) imbedding AgNPs into the hybrid sol network.

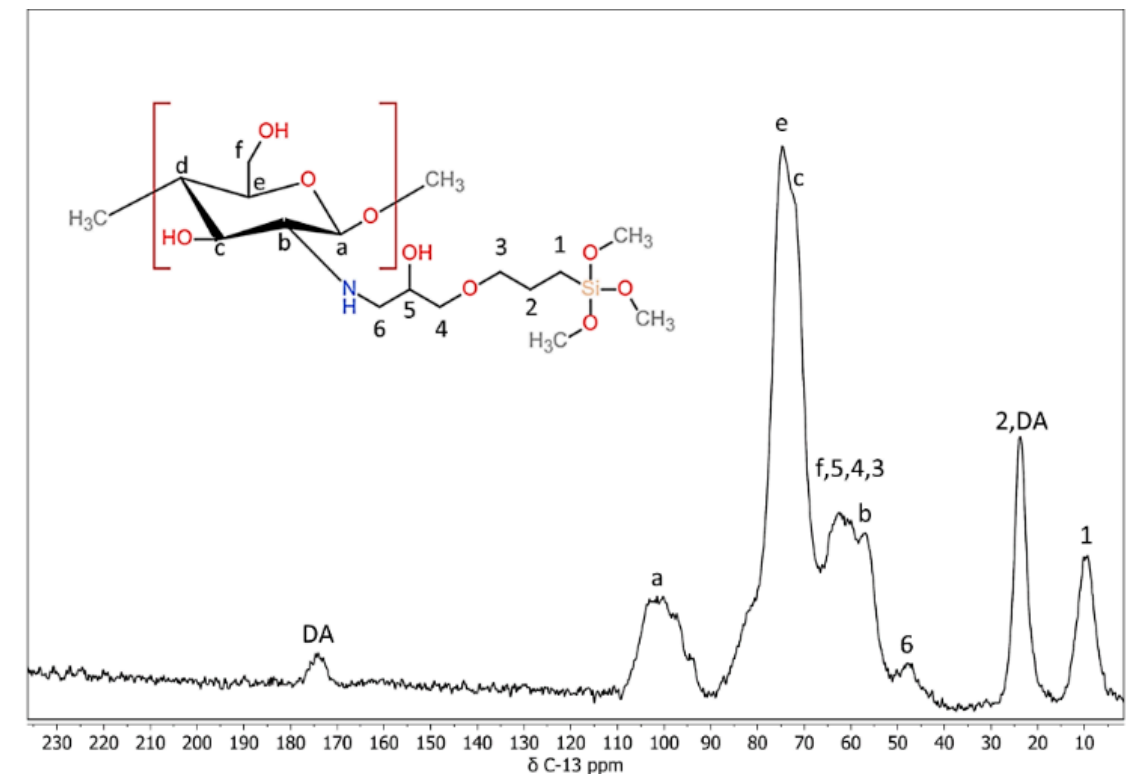

Figure 3. Characterization of covalent coupling in hybrid materials. ${ }^{13} \mathrm{C}$ Magic-angle spinning nuclear magnetic resonance (MAS-NMR) spectra of the hybrid material. Covalent coupling was confirmed by peak " 6 ", which was from a nucleophilic attack of the primary amine in chitosan on the epoxide of 3-glycidyloxypropyltrimethoxysilane (GPTMS). The absence of other peaks associated with coupling of these species indicated that the amine in chitosan was the sole site of coupling. 
As a method to conveniently measure the degree of covalent coupling between chitosan and GPTMS, a ninhydrin assay was utilized (Figure 4). This assay enabled the detection of primary amine groups that may have remained uncoupled during the development of the hybrid materials. Through this colorimetric assay, the transformation of primary amines in the deacetylated units of chitosan to secondary amines upon coupling with the epoxide functional group of GPTMS, could be monitored.

A standard curve was established with the batch of chitosan used in this study, which had an $82 \%$ degree of deacetylation. It was compared to the chitosan coupled with GPTMS and showed that a 91\% degree of crosslinking between chitosan and GPTMS was achieved. This high degree of coupling was closely monitored and maintained throughout the study, as variations in covalent coupling can yield large variations in the mechanical and thermomechanical properties of the resulting hybrid materials [58].

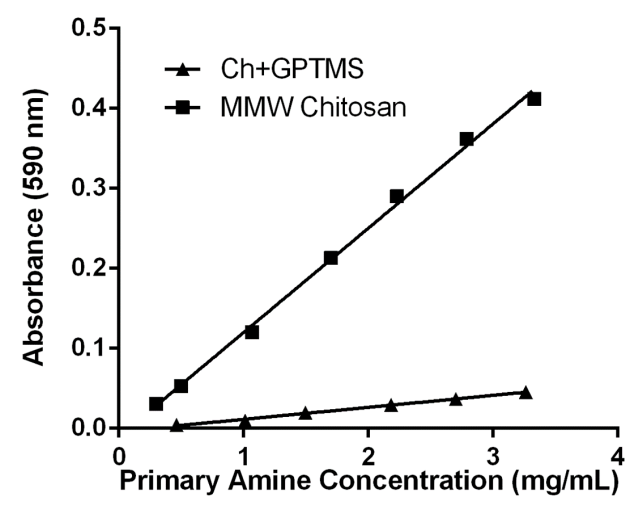

Figure 4. Quantitative analysis of covalent coupling between chitosan and 3-glycidyloxypropyltrimethoxysilane (GPTMS) by ninhydrin assay. In finely ground aqueous suspensions of coupled material (Ch+GPTMS) and uncoupled chitosan (MMW Chitosan), ninhydrin reagents selectivity for primary amines was measured by optical absorbance at $590 \mathrm{~nm}$. The degree of covalent coupling between chitosan and GPTMS was measured to be $91 \%$ and maintained throughout the study.

SEM was utilized to examine the roughened surface morphologies and microtopographies of the hybrid coating films (Figure 5A). A common standardized acid-etching protocol was applied to bare titanium to achieve a roughened substrate topography. To coat these roughened Ti6Al4V substrates, a dip coating protocol was utilized that has been shown to effectively deposit thin films from hybrid sols [59-61]. The thinness of the hybrid coating films ensured that there was a degree of roughness attributed to their acid-etched substrates. The coated surfaces retained a degree of microscale roughness that has been shown to provide a positive topographical stimulus for cell interactions and bone apposition [62-64].

The accompanying EDX analyses and elemental mapping of silicon, oxygen, nitrogen, carbon and silver (Figure 5B-F)) showed their distribution across the coated surfaces. All elements were found to be homogeneously distributed throughout the coating matrix for all samples. The distribution of silicon (Figure 5B) confirmed the presence of silanol and siloxane networks in the hybrid coatings and their homogenous nature throughout the matrix. The distribution of nitrogen (Figure 5D) and carbon (Figure 5E) confirmed the presence of an organic chitosan network that was homogenously integrated throughout the coatings. Additionally, the detection of silver (Figure 5F) confirmed the successful incorporation and homogenous distribution of antimicrobial AgNPs throughout the coating matrix. 

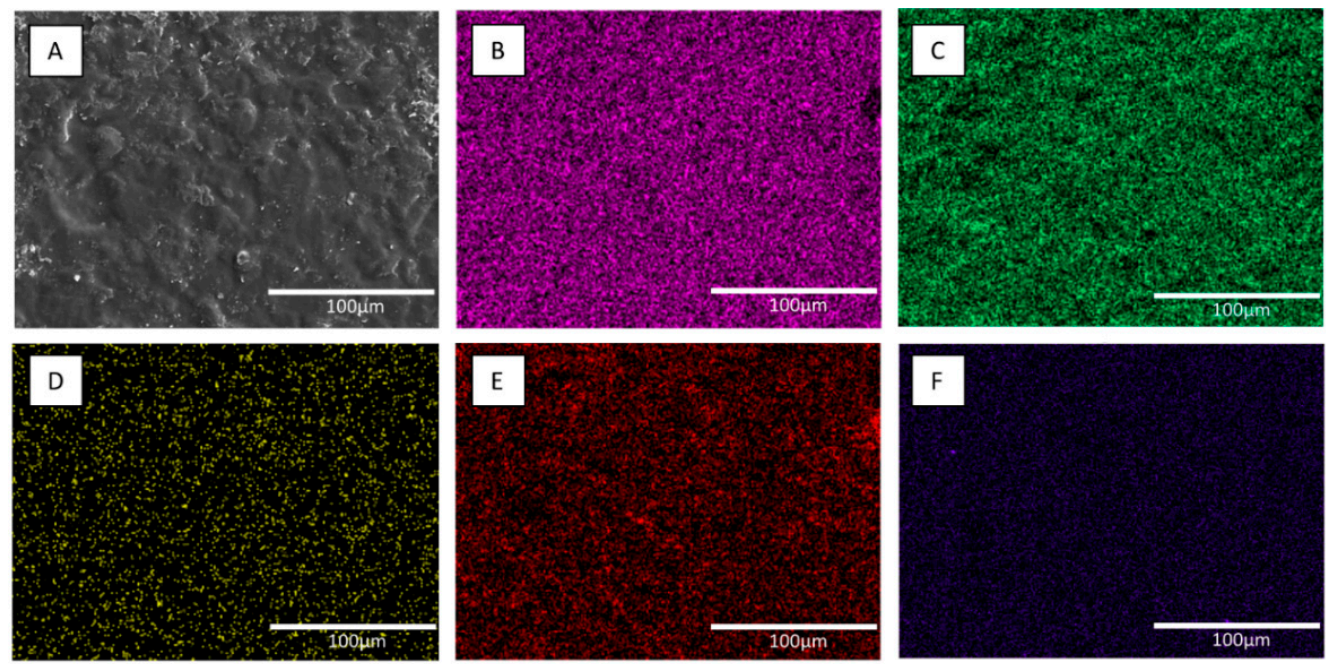

Figure 5. Scanning electron microscopy (SEM) and elemental (EDX) analysis of the $40 \% \mathrm{ChSi}-\mathrm{nAg}$ hybrid coating. SEM showed smooth undulating contours and microtopographies (A). EDX mapping detected a homogenous distribution of silicon (B), oxygen (C), nitrogen (D), carbon (E) and silver (F). The SEM/EDX analyses were representative and consistent across all coatings. Scale bar: $100 \mu \mathrm{m}$.

The AgNPs was synthesized through supplementary procedures. Their nanoscale dimensions were confirmed by transmission electron microscopy (TEM). Micrographs (Figure 6A) showed that all synthesized nanoparticles were under $100 \mathrm{~nm}$ in size and UV spectroscopy (Figure 6B) confirmed the consistency of their colloidal suspensions. The PVP-capped nanoparticles synthesized in this study, were maintained within 10-20 nm and exhibited long-term colloidal stability in aqueous solutions, before being incorporated into the chitosan-silica hybrid sol-gel system for coating.
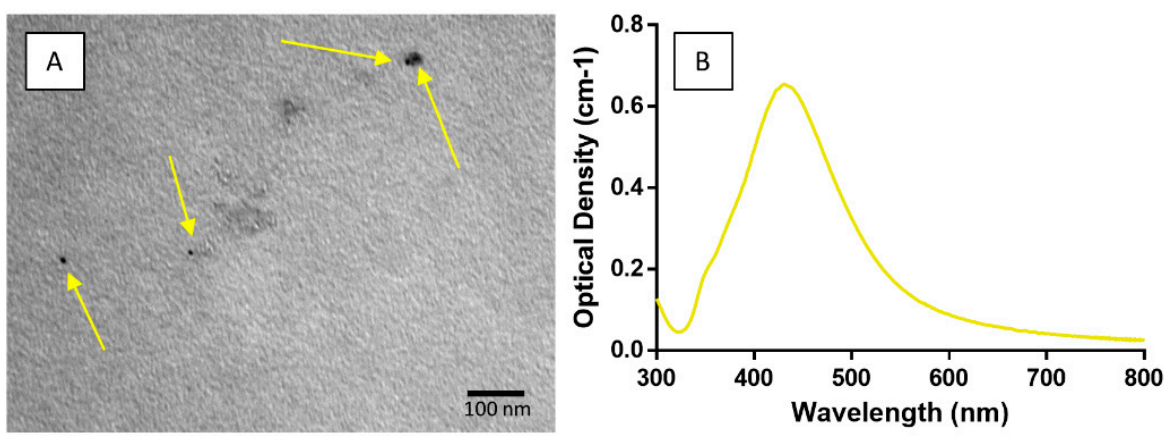

Figure 6. Evaluation of synthesized AgNPs. (A) Transmission electron microscopy (TEM) confirmed nanoscale particle sizes. (B) UV spectroscopy of AgNP suspensions verified their consistency.

Through the utilization of class II covalent coupling reactions, highly homogenous hybrid coatings were created. The homogenous coating matrices are consistent with enhanced mechanical properties. In contrast, coating materials that lack homogeneity have been shown to have inconsistent mechanical properties and result in areas across coating surfaces that have inconsistent resorption properties $[65,66]$. Indeed, a lack of homogeneity in the HAp coating materials that are currently available has limited their clinical usage and success. They have been shown to suffer from phase inconsistency and resultant discrepancies in their mechanical properties [67,68].

ATR-FTIR analyses were used to compare the variation in chemical properties between different coating blends (Figure 7). For pure chitosan, the peaks associated with the stretching of the primary and secondary amines were identified at 1526 and $1635 \mathrm{~cm}^{-1}$, respectively. As expected, these peaks decreased in intensity as the organic content of the hybrid coating blends decreased $(80 \%, 60 \%, 40 \%$ and $20 \% \mathrm{ChSi}$ ), and were completely absent for the purely inorganic TEOS-based material. When comparing 
the intensity of these peaks for pure chitosan and the coupled chitosan samples (Ch+GPTMS), there was a decrease observed in the relative intensities for the primary amine in chitosan and no change for the secondary amine. This showed that the coupling reaction had only occurred between the primary amine in chitosan and GPTMS, confirming the findings of ${ }^{13} \mathrm{C}$ MAS-NMR and the ninhydrin assay.

Additionally, the incorporation of GPTMS into these hybrid materials was detected by the bond stretching associated with the epoxide group identified at $910 \mathrm{~cm}^{-1}$ (Figure 7). This epoxide peak was observed in pure coupled samples (Ch+GPTMS) and faintly in the more highly organic blends ( $80 \%$ and $60 \% \mathrm{ChSi}$ ). As the inorganic fraction increased, this peak was progressively eclipsed by the consequent stretching of the silanol species at $935 \mathrm{~cm}^{-1}$. The incorporation of silane species into the hybrid coatings was observed as peaks from the stretching of the $\mathrm{Si}-\mathrm{OH}$ bond at 774 and $935 \mathrm{~cm}^{-1}$ in the hydrolyzed material and the stretching of the Si-O-Si bonds at $1065 \mathrm{~cm}^{-1}$ from condensed siloxane. As expected, the presence of these peaks became more prevalent as the organic content decreased in the hybrid coating blends.

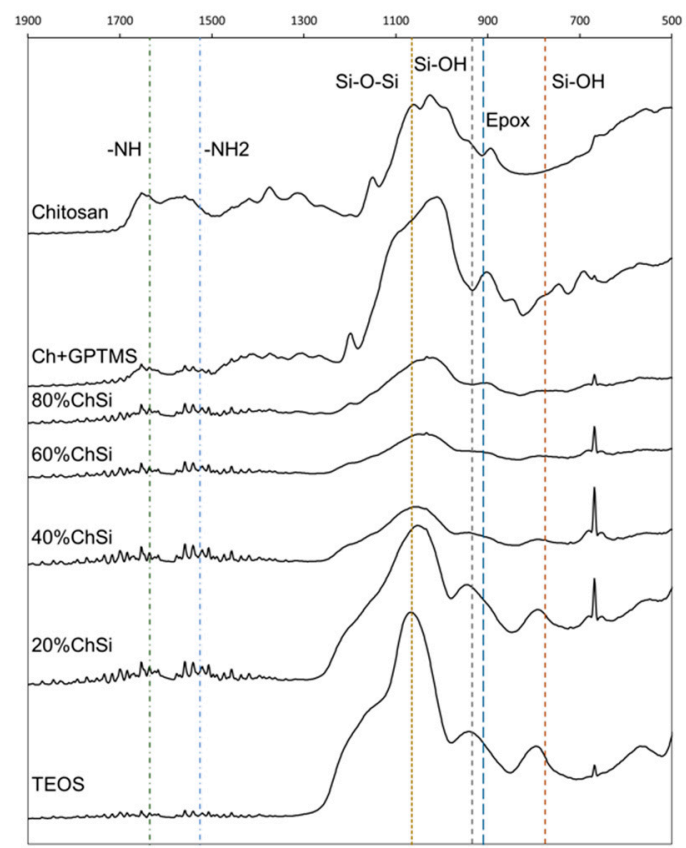

Figure 7. Infrared analyses of chemical structures in hybrid materials. Total reflectance Fourier transform infrared (ATR-FTIR) spectra of chitosan, chitosan coupled with 3-glycidyloxypropyltrimethoxysilane (Ch+GPTMS), hybrid materials (80-20\% ChSi) and pure inorganic siloxane (condensed TEOS). There were more peaks attributed to chitosan and GPTMS (-NH, $-\mathrm{NH}_{2}$, Epox) for hybrid materials with higher organic content. Their chemical characteristics were more similar to a purely inorganic siloxane network $(\mathrm{Si}-\mathrm{O}-\mathrm{Si}, \mathrm{Si}-\mathrm{OH})$, as the organic fraction decreased.

\subsection{Mechanical Properties}

For all biomaterials, surface interactions with surrounding physiological fluids that may include the adsorption of serum proteins, are an important determinant of subsequent cellular responses and the ingrowth of host tissues [69]. To predict these interactions, the measurement of water contact angles on the biomaterial surfaces are an effective metric. Surfaces with contact angles between $60^{\circ}$ and $85^{\circ}$ are intermediate in hydrophilicity, and have been shown to facilitate the most favorable interactions with host tissues through enhanced cell growth and proliferation $[59,70,71]$.

All hybrid coatings that were developed in this study had an intermediate degree of hydrophilicity (Figure 8$)$. The coating blend with the least organic content $(20 \% \mathrm{ChSi})$ had the largest water contact angle and was a little more hydrophobic than the $60 \%$ ChSi blend, which had the smallest contact angle and was the most hydrophilic. However, these differences between the blends were small and not 
statistically significant $(p>0.05)$. However, all coatings had contact angles that were larger than their uncoated acid-etched Ti6Al4V substrate and these differences were statistically significant $(p<0.05)$. Although the coating blends contained many hydrophilic chemistries due to their chitosan content and the remaining silanol linkages, the bare acid-etched Ti6Al4V substrates had a high degree of surface roughness, which enhanced their wettability. For such wettable surfaces (contact angles $<90^{\circ}$ ), an increase in surface roughness has been reported to enhance their hydrophilicity [72]. The acid-etching of Ti6Al4V substrates created numerous pits and valleys ranging in size from 10-40 $\mu \mathrm{m}$ (Figure 9), which enhanced their surface roughness and thereby their hydrophilicity. The deposition of coatings on these substrates partially filled these pits and valleys, which reduced their surface roughness and increased water contact angles.
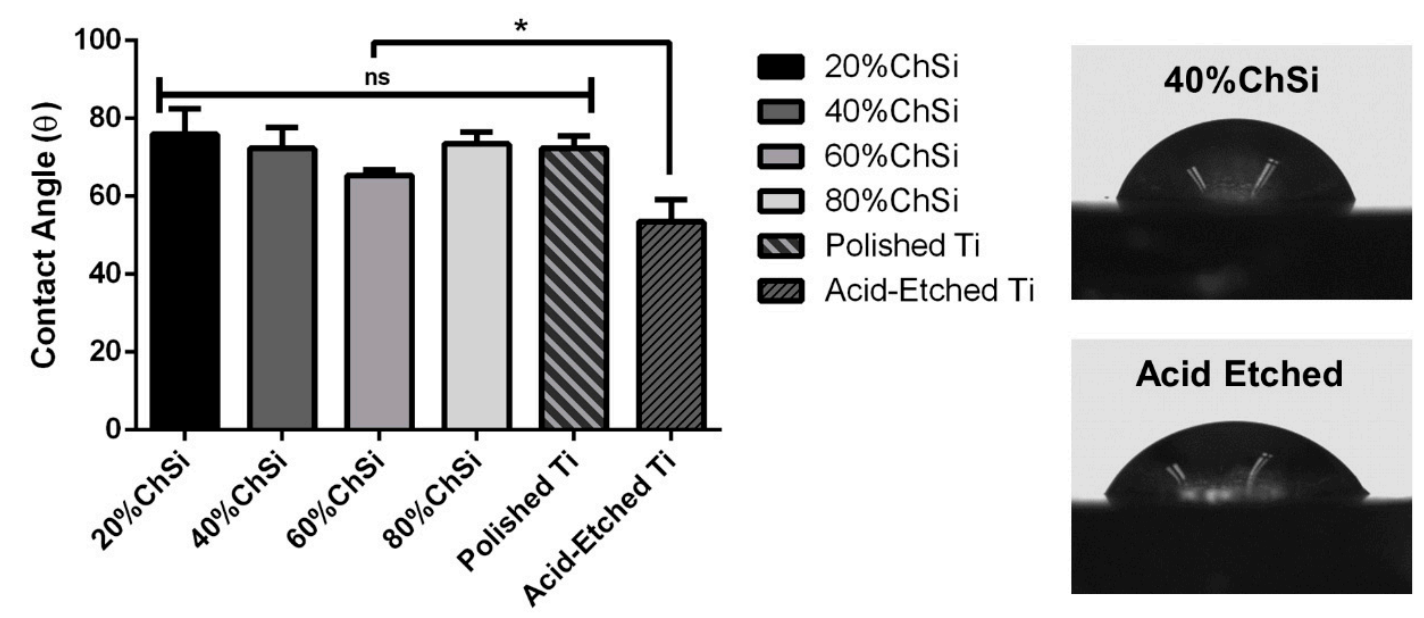

Figure 8. Water contact angles for coatings and titanium (Ti6Al4V) substrates. Static water contact angles ( $n=5 /$ surface) for all coatings and polished Ti6Al4V were similar with an intermediate degree of hydrophilicity. Contact angles for acid-etched Ti6Al4V were significantly $(p<0.05)$ lower and more hydrophilic. ns—not significantly different; ${ }^{*}$ - statistically significant different.
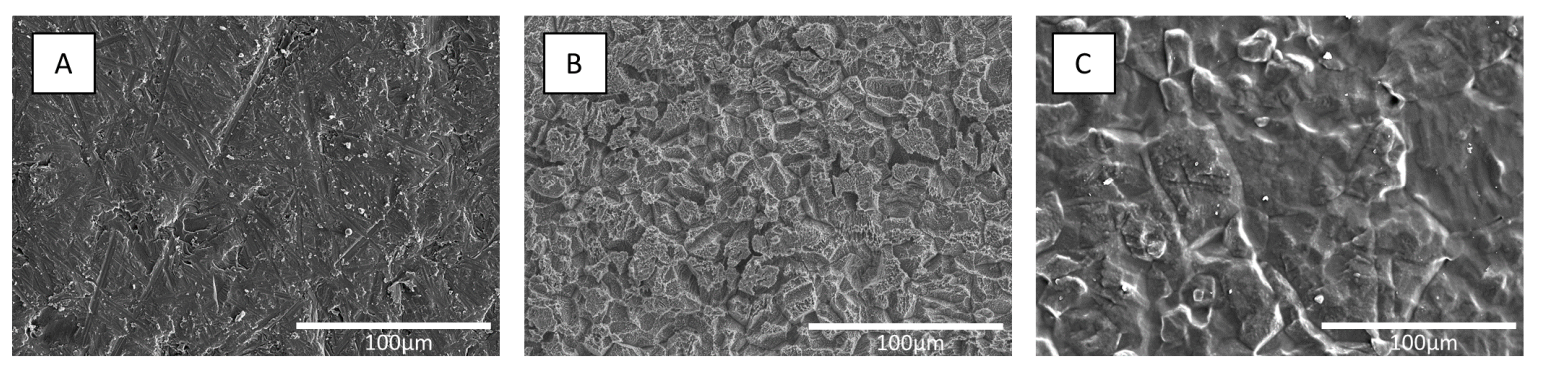

Figure 9. Scanning electron microscopy (SEM) of titanium (Ti6Al4V) substrates and coated surfaces. (A) Polished Ti6Al4V was flat with smoothly scalloped surfaces; (B) acid-etched Ti6Al4V had extensive surface fissures that created microscale roughness; (C) hybrid coating (60\% ChSi) films on acid-etched Ti6Al4V substrates retained microtopographical features and surface roughness. SEM analyses were representative and consistent across all coatings.

Biomaterial coatings also require adequate adhesive bond strength to their underlying substrates, which is an important parameter that is often overlooked in many studies. Poor adhesive strength may lead to delamination of the coating, which then causes inflammation, bone resorption, loosening of the fixtures and eventually the failure of intraosseous implants [73,74].

Initially, the adhesion of the hybrid coatings to Ti6Al4V substrates was evaluated by a cross-hatch delamination protocol as described in ASTM D3359. This method provided a coarse assessment of overall coating adhesion. Additionally, the scoring of the coating materials imparted stresses within their structure, which manifest as extensive cracks and fissures across the surfaces of the purely 
inorganic controls (Figure 10C,D). The purely inorganic coatings were brittle, and cross-hatch testing had led to a widespread cracking of their thin films. In clinical applications, the impact of sharp boney protrusions and/or surgical instruments could lead to a premature failure of such coatings in vivo [75]. In contrast, all hybrid coatings exhibited highly robust, intact and integrated surfaces, despite the surface scoring (Figure 10A,B).

Additionally, more rigorous and quantitative evaluations of coating adhesion and risk of delamination were performed by adhesive tensile tests based on established protocols $[55,76]$. All coatings were assessed for their adhesion to both polished and acid-etched Ti6Al4V substrates (Figure 11). All hybrid coatings were significantly $(p<0.05)$ more adherent to acid-etched Ti6Al4V substrates than to polished titanium. Furthermore, all coating blends that contained AgNPs exhibited identical adhesion characteristics to those without these antimicrobial additives (excluded from figure to ensure clarity). As expected, acid-etching like other surface roughening pretreatments, enhances adherence to the modified substrate [77-79]. This has been attributed to the increase in bonding area by roughening pretreatments, which thereby enhance the mechanical adhesion of coatings to their substrates. However, purely organic chitosan control coatings showed only a small, statistically insignificant $(p>0.05)$ increase in adhesion to the acid-etched substrate compared to polished Ti6Al4V. This may have been due to the high viscosity of pure chitosan, which led to poor wetting of Ti6Al4V substrates, and lower overall mechanical adhesion compared to that of hybrid coating blends [79].

Among implant coating materials that are commercially available, plasma sprayed hydroxyapatite (HA) surfaces remain a gold standard for intraosseous applications. However, their preparations involve high temperatures and variable cooling cycles, which retain residual stresses that contribute to failures from adhesive forces of less than $10 \mathrm{MPa}$ [80-82]. Therefore, the robust adhesion (16-18 MPa) for all hybrid coatings deposited on acid-etched Ti6Al4V that were developed in this research, warrant further study.
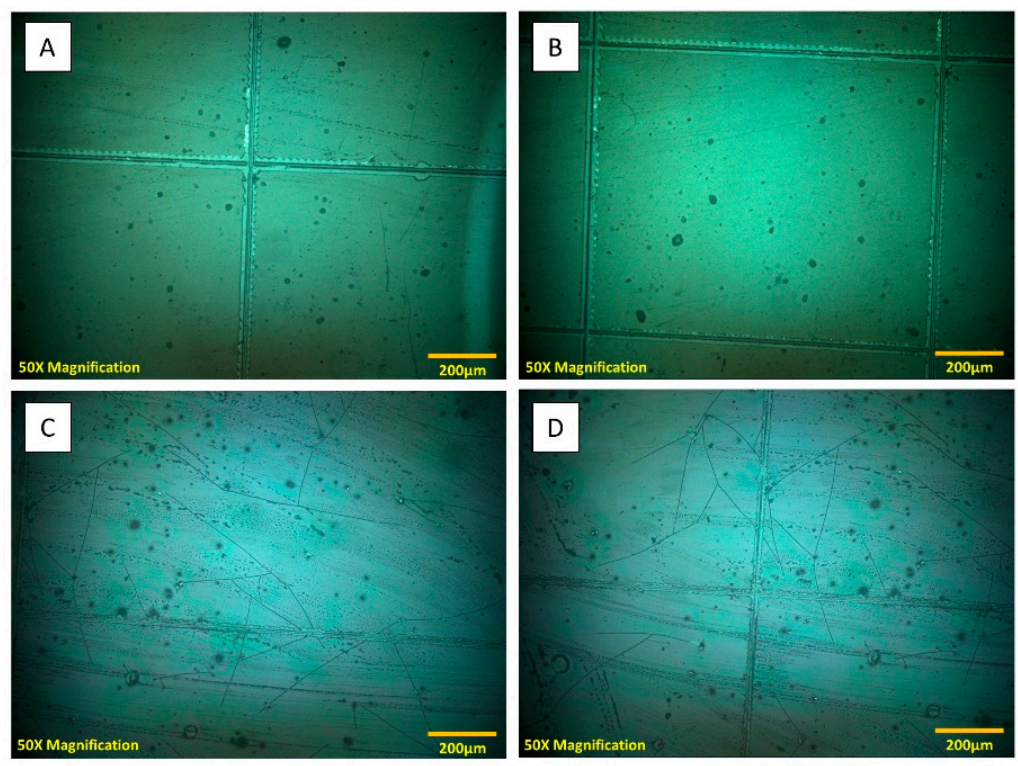

Figure 10. Microscopic examination of coatings in cross-hatch tests of adhesion. (A,B) Coating $(60 \% \mathrm{ChSi})$ surfaces were unblemished by full-depth incisions in the standardized cross-hatch adhesion protocol; (C,D) inorganic siloxane material (control) developed extensive arrays of surface cracks and fissures from the same cross-hatch testing protocol. Adhesion of the $60 \% \mathrm{ChSi}$ coating blend was representative and consistent across all hybrid coatings. 


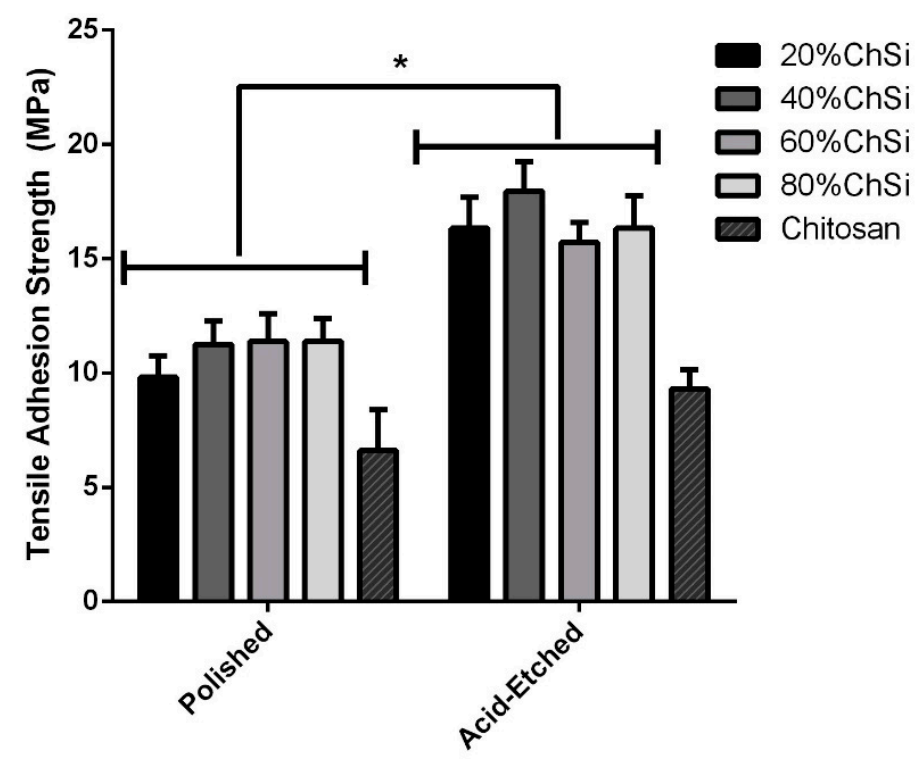

Figure 11. Adhesive tensile strengths of coatings and chitosan on titanium (Ti6Al4V) substrates. All hybrid coatings ( $n=3$ /surface) had significantly $(p<0.05)$ more adhesion to acid-etched than to polished Ti6Al4V substrates. All hybrid coatings were more adhesive than pure chitosan to both polished and acid-etched Ti6Al4V. ${ }^{*}$ - statistically significant difference

\subsection{Antimicrobial Properties}

As bacterial infections are the most common cause of implant failure [7-9], the application of antimicrobial surface coatings may afford a valuable feature for implantable materials. Therefore, the coatings in this study were prepared with chitosan as the main organic constituent, which naturally displays some antimicrobial activity. Additionally, some of these coatings were loaded with AgNPs as additives that could further enhance their antimicrobial effects. Antimicrobial efficacies were evaluated on S. aureus and E. coli cultures, which are common Gram-positive and Gram-negative bacterial pathogens, respectively, associated with various bodily infections.

Interestingly, the $S$. aureus and E. coli cultures were only minimally affected by the base coatings that had not been loaded with AgNPs (Figure 12). However, E. coli growth was markedly reduced over $24 \mathrm{~h}$, and S. aureus growth was completely suppressed for $24 \mathrm{~h}$, with all coatings that contained AgNPs.
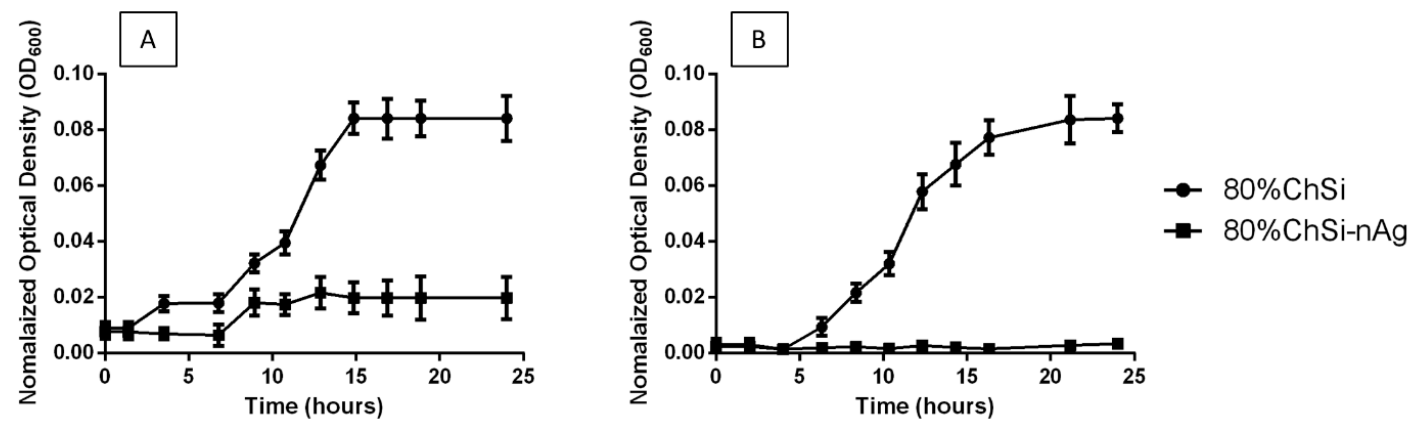

Figure 12. Inhibition of bacterial growth in planktonic cultures. There was a (A) marked reduction in E. coli growth and (B) complete inhibition of S. aureus grown in the presence of $80 \% \mathrm{ChSi}$-nAg compared to $80 \% \mathrm{ChSi}$. This inhibition of bacterial growth by $80 \% \mathrm{ChSi}-\mathrm{nAg}$ was representative and consistent for all hybrid coatings that contained AgNPs.

The quantitative assessments of these bacterial cultures following $24 \mathrm{~h}$ incubations with hybrid coatings showed that there had been some inhibition by all coatings, when compared to uncoated titanium controls (Figure 13). The planktonic E. coli and S. aureus cultures were almost completely 
inhibited (80-100\% and 75-77\%, respectively) by the presence of coatings that had been loaded with AgNPs. Indeed, coatings loaded with AgNPs were significantly $(p<0.05)$ more effective than base coatings without AgNPs, which had only minimal antibacterial effects $(<30 \%)$. These results indicated that release-based mechanisms were involved in the antimicrobial properties of the hybrid coatings. They were bacteriostatic and/or bactericidal effects on some of the most common bacterial pathogens that cause opportunistic infections.

Additionally, coatings loaded with AgNPs appeared to have been more effective against E. coli cultures, than $S$. aureus. This difference may have been due to the release-based antimicrobial action of AgNPs through the different cell wall structures of these bacteria. Unlike Gram-negative E. coli planktonic cells, Gram-positive bacteria such as S. aureus are protected from their external environment by much thicker peptidoglycan layers within their cell walls [83]. These cell walls may have partially limited the internalization of AgNPs and retarded their release-based action. Similarly, previous studies have reported that Gram-negative bacteria experienced more membrane damage and oxidative stress in response to the release-based action of AgNPs, than Gram-positive bacteria [84-86].
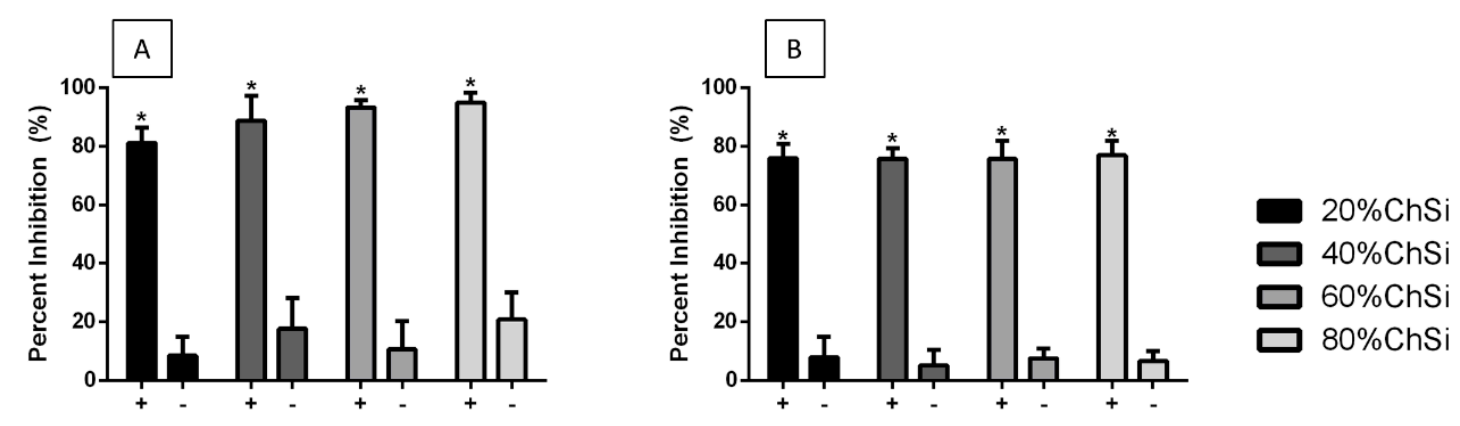

Figure 13. Inhibition of bacterial cultures by hybrid coatings with (+) and without (-) AgNPs. (A) E. coli and (B) S. aureus cultures were inhibited by incubation $(24 \mathrm{~h})$ with all hybrid coatings, compared to uncoated titanium (Ti6Al4V) controls. There was little inhibition from base coatings without AgNPs, but significantly $(p<0.05)$ more and almost total inhibition for coatings loaded with AgNPs.

In addition to the virulence of planktonic cells within bacterial cultures, these pathogens can be particularly pernicious due to their formation of highly adherent biofilms on biomaterial surfaces. In contrast to cells suspended in culture, bacteria encased within biofilms are highly resistant to mechanical dislodgement and antibiotic treatment $[8,10]$. Therefore, E. coli and S. aureus biofilm formation on coatings were carefully compared to uncoated Ti6Al4V controls for inhibitory effects.

Indeed, both E. coli and S. aureus were clearly inhibited for at least $24 \mathrm{~h}$ in their formation of biofilms on all hybrid coatings, compared to uncoated Ti6Al4V controls (Figure 14). Base coatings alone were moderately effective at inhibiting E. coli biofilm formation on their surfaces (31-50\%) and were even more effective against S. aureus (38-80\%). However, the coatings loaded with AgNPs were markedly more effective at inhibiting E. coli biofilm formation (60-95\%), and almost completely effective against $S$. aureus $(90-95 \%)$. The coatings with AgNPs were significantly $(p<0.05)$ more effective than their unloaded controls for all blends, except those that had a high organic chitosan content. This accompanied the positive trend of greater antimicrobial activity with increasing chitosan content. As chitosan is a naturally antimicrobial polysaccharide, its role in the coating network was expected to have had this effect on both the inhibition of biofilm formation and the inhibition of bacterial cultures [87].

The larger inhibition of $S$. aureus compared to E. coli biofilms contrasted with the reduced susceptibility of $S$. aureus than E. coli cells in culture. This may have been due to differences in their development of extracellular polymeric substances (EPS). Mainly composed of polysaccharides and proteins, the EPS produced by sessile colonies of bacteria has been shown to be a key component in their resistance to antibiofilm agents such as cationic peptides and metal ions [88]. Additionally, the EPS production of sessile colonies has been shown to be enhanced when colonies adhere to toxic 
surfaces [89]. Therefore, the sessile colonies of E. coli may have provided some resistance to the coatings by producing more EPS during biofilm formation. Indeed, prior studies have reported that E. coli exhibit rapid EPS formation when compared to their Gram-positive counterparts, leading to a more effective resistance in their sessile state $[84,90]$.
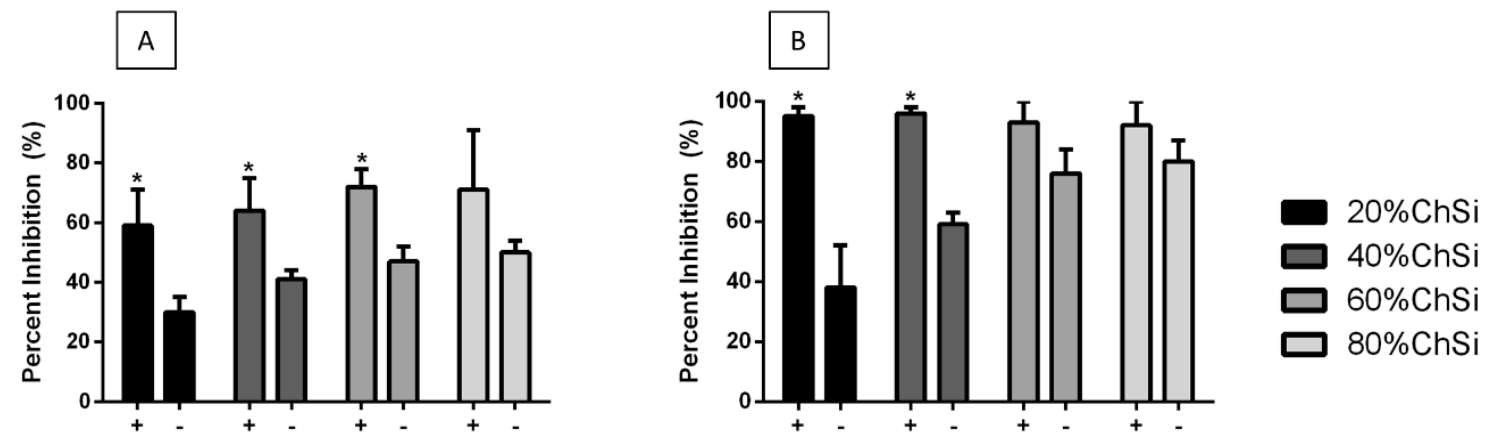

Figure 14. Inhibition of bacterial biofilm formation on hybrid coatings with (+) and without (-) AgNPs. (A) E. coli and (B) S. aureus biofilm formation $(24 \mathrm{~h})$ were inhibited on all hybrid coatings, compared to uncoated titanium (Ti6Al4V) controls. Inhibition of biofilm formation was greater on coatings that contained AgNPs and was generally more on coatings with higher organic content. There was near complete inhibition of $S$. aureus biofilms on all hybrid coatings that contained AgNPs.

\section{Conclusions}

In this study, chitosan-silica class II hybrid materials were developed as thin film coatings for implantable Ti6A14V surfaces. Additionally, the hybrid coatings were effectively loaded with AgNPs for antimicrobial applications. Their chemical structures and composition were confirmed by MAS-NMR, FTIR and EDX analyses. Surface microtopographies, mechanical properties and wettability were evaluated by SEM, adhesive tensile testing and water contact angles. Antimicrobial properties were assessed in E. coli and S. aureus cultures and on their biofilm formation.

The hybrid coatings demonstrated strong covalent linkages between their organic chitosan backbone and the silica inorganic network. There was a homogenous dispersion of elements, including AgNP additives, across their surfaces. Hybrid coatings demonstrated a robust resistance to fracture and dislodgement and were highly adherent to acid-etched Ti6Al4V substrates, especially when compared to purely organic or inorganic materials. They exhibited moderate levels of roughness, microtopography and wettability when compared with uncoated Ti6Al4V surfaces. All hybrid coatings displayed some antimicrobial effects and greater organic chitosan content was associated with increased bacterial inhibition. Additionally, coatings loaded with AgNPs showed marked inhibition of planktonic bacteria and their biofilms, with near complete inhibition of E. coli cultures and of S. aureus biofilm formation. These robust, retentive and antimicrobial coatings for implantable titanium materials were based on rudimentary chitosan-silica coupling processes, which may afford a novel strategy for biomaterial applications.

Author Contributions: Conceptualization, Z.G. and J.Z.; methodology, Z.G and J.Z.; formal analysis, Z.G. and H.P.; data curation, Z.G. and H.P.; writing-original draft preparation, Z.G.; writing-review \& editing, Z.G. and H.P.; visualization, Z.G. and H.P.; supervision, J.Z.; funding acquisition, J.Z. All authors have read and agreed to the published version of the manuscript.

Funding: This research was funded by the Natural Sciences and Engineering Research Council of Canada (NSERC) Discovery Grant (Grant No. RGPIN-2019-07,314).

Conflicts of Interest: The authors declare no conflicts of interest. 


\section{References}

1. Greger, M.; Widomská, M.; Snášel, V. Structure and properties of dental implants. In Proceedings of the METAL 2012-21st International Conference on Metallurgy and Materials, Brno, Czech Republic, 23-25 May 2012; Volume 120, pp. 434-439.

2. Darouiche, R.O. Treatment of infections associated with surgical implants. Infect. Dis. Clin. Pract. 2004, 12, 258-259. [CrossRef] [PubMed]

3. Chouirfa, H.; Bouloussa, H.; Migonney, V.; Falentin-daudré, C. Review of titanium surface modification techniques and coatings for antibacterial applications. Acta Biomater. 2019, 83, 37-54. [CrossRef] [PubMed]

4. Camps-Font, O.; Figueiredo, R.; Valmaseda-Castellón, E.; Gay-Escoda, C. Postoperative infections after dental implant placement: Prevalence, clinical features, and treatment. Implant. Dent. 2015, 24, 713-719. [CrossRef] [PubMed]

5. Mah, T.F.; Pitts, B.; Pellock, B.; Walker, G.C.; Stewart, P.S.; O'Toole, G.A. A genetic basis for Pseudomonas aeruginosa biofilm antibiotic resistance. Nature 2003, 426, 306-310. [CrossRef] [PubMed]

6. Yoda, I.; Koseki, H.; Tomita, M.; Shida, T.; Horiuchi, H.; Sakoda, H.; Osaki, M. Effect of surface roughness of biomaterials on Staphylococcus epidermidis adhesion. BMC Microbiol. 2014, 14, 234. [CrossRef] [PubMed]

7. Privett, B.J.; Youn, J.; Hong, S.A.; Lee, J.; Han, J.; Shin, J.H.; Schoenfisch, M.H. Antibacterial fluorinated silica colloid superhydrophobic surfaces. Langmuir 2011, 27, 9597-9601. [CrossRef]

8. Yu, K.; Lo, J.C.Y.; Yan, M.; Yang, X.; Brooks, D.E.; Hancock, R.E.W.; Lange, D.; Kizhakkedathu, J.N. Anti-adhesive antimicrobial peptide coating prevents catheter associated infection in a mouse urinary infection model. Biomaterials 2017, 116, 69-81. [CrossRef]

9. Swartjes, J.J.T.M.; Sharma, P.K.; Kooten, T.G.; Mei, H.C.; Mahmoudi, M.; Busscher, H.J.; Rochford, E.T.J. Current developments in antimicrobial surface coatings for biomedical applications. Curr. Med. Chem. 2014, 22, 2116-2129. [CrossRef]

10. Radin, S.; Ducheyne, P. Controlled release of vancomycin from thin sol-gel films on titanium alloy fracture plate material. Biomaterials 2007, 28, 1721-1729. [CrossRef]

11. Bračič, M.; Fras-Zemljič, L.; Pérez, L.; Kogej, K.; Stana-Kleinschek, K.; Kargl, R.; Mohan, T. Protein-repellent and antimicrobial nanoparticle coatings from hyaluronic acid and a lysine-derived biocompatible surfactant. J. Mater. Chem. B 2017, 5, 3888-3897. [CrossRef]

12. Zhang, X.; Chaimayo, W.; Yang, C.; Yao, J.; Miller, B.L.; Yates, M.Z. Silver-hydroxyapatite composite coatings with enhanced antimicrobial activities through heat treatment. Surf. Coat. Technol. 2017, 325, 39-45. [CrossRef]

13. Tabesh, E.; Salimijazi, H.; Kharaziha, M.; Hejazi, M. Antibacterial chitosan-copper nanocomposite coatings for biomedical applications. Mater. Today Proc. 2018, 5, 15806-15812. [CrossRef]

14. Stewart, P.S.; William Costerton, J. Antibiotic resistance of bacteria in biofilms. The Lancet 2001, 358, 135-138. [CrossRef]

15. Jones, N.; Ray, B.; Ranjit, K.T.; Manna, A.C. Antibacterial activity of ZnO nanoparticle suspensions on a broad spectrum of microorganisms. FEMS Microbiol. Lett. 2008, 279, 71-76. [CrossRef] [PubMed]

16. Rai, M.; Kon, K.; Ingle, A.; Duran, N.; Galdiero, S.; Galdiero, M. Broad-spectrum bioactivities of silver nanoparticles: The emerging trends and future prospects. Appl. Microbiol. Biotechnol. 2014, 98, 1951-1961. [CrossRef] [PubMed]

17. Kim, J.S.; Kuk, E.; Yu, K.N.; Kim, J.H.; Park, S.J.; Lee, H.J.; Kim, S.H.; Park, Y.K.; Park, Y.H.; Hwang, C.Y.; et al. Antimicrobial effects of silver nanoparticles. Nanomed. Nanotechnol. Biol. Med. 2007, 3, 95-101. [CrossRef] [PubMed]

18. Lara, H.H.; Ayala-Núñez, N.V.; del Turrent, L.C.I.; Padilla, C.R. Bactericidal effect of silver nanoparticles against multidrug-resistant bacteria. World J. Microbiol. Biotechnol. 2010, 26, 615-621. [CrossRef]

19. Zhao, L.; Wang, H.; Huo, K.; Cui, L.; Zhang, W.; Ni, H.; Zhang, Y.; Wu, Z.; Chu, P.K. Antibacterial nano-structured titania coating incorporated with silver nanoparticles. Biomaterials 2011, 32, 5706-5716. [CrossRef]

20. Woo, K.J.; Hye, C.K.; Ki, W.K.; Shin, S.; So, H.K.; Yong, H.P. Antibacterial activity and mechanism of action of the silver ion in Staphylococcus aureus and Escherichia coli. Appl. Environ. Microbiol. 2008, 74, 2171-2178. [CrossRef] 
21. Kvítek, L.; Panáček, A.; Soukupová, J.; Kolář, M.; Večeřová, R.; Prucek, R.; Holecová, M.; Zbořil, R. Effect of surfactants and polymers on stability and antibacterial activity of silver nanoparticles (NPs). J. Phys. Chem. C 2008, 112, 5825-5834. [CrossRef]

22. Sotiriou, G.A.; Pratsinis, S.E. Antibacterial activity of nanosilver ions and particles. Environ. Sci. Technol. 2010, 44, 5649-5654. [CrossRef] [PubMed]

23. Ong, J.L.; Lucas, L.C. Post-deposition heat treatments for ion beam sputter deposited calcium phosphate coatings. Biomaterials 1994, 15, 337-341. [CrossRef]

24. Li, T.; Lee, J.; Kobayashi, T.; Aoki, H. Hydroxyapatite coating by dipping method, and bone bonding strength. J. Mater. Sci. Mater. Med. 1996, 7, 355-357. [CrossRef]

25. Wang, B.C.; Lee, T.M.; Chang, E.; Yang, C.Y. The shear strength and the failure mode of plasma-sprayed hydroxyapatite coating to bone: The effect of coating thickness. J. Biomed. Mater. Res. 1993, 27, 1315-1327. [CrossRef]

26. Hamedi, H.; Moradi, S.; Hudson, S.M.; Tonelli, A.E. Chitosan based hydrogels and their applications for drug delivery in wound dressings: A review. Carbohydr. Polym. 2018, 199, 445-460. [CrossRef]

27. Quiñones, J.P.; Peniche, H.; Peniche, C. Chitosan based self-assembled nanoparticles in drug delivery. Polymers 2018, 10, 235. [CrossRef]

28. Wang, T.; Hou, J.; Su, C.; Zhao, L.; Shi, Y. Hyaluronic acid-coated chitosan nanoparticles induce ROS-mediated tumor cell apoptosis and enhance antitumor efficiency by targeted drug delivery via CD44. J. Nanobiotechnology 2017, 15, 7. [CrossRef]

29. Oryan, A.; Sahvieh, S. Effectiveness of chitosan scaffold in skin, bone and cartilage healing. Int. J. Biol. Macromol. 2017, 104, 1003-1011. [CrossRef]

30. Zhang, J.; Lu, X.; Feng, G.; Gu, Z.; Sun, Y.; Bao, G.; Xu, G.; Lu, Y.; Chen, J.; Xu, L.; et al. Chitosan scaffolds induce human dental pulp stem cells to neural differentiation: Potential roles for spinal cord injury therapy. Cell Tissue Res. 2016, 366, 129-142. [CrossRef]

31. Saravanan, S.; Sareen, N.; Abu-El-Rub, E.; Ashour, H.; Sequiera, G.L.; Ammar, H.I.; Gopinath, V.; Shamaa, A.A.; Sayed, S.S.E.; Moudgil, M.; et al. Graphene oxide-gold nanosheets containing chitosan scaffold improves ventricular contractility and function after implantation into infarcted heart. Sci. Rep. 2018, 8, 1-13. [CrossRef]

32. Vil'Danova, R.R.; Sigaeva, N.N.; Kukovinets, O.S.; Volodina, V.P.; Spirikhin, L.V.; Zaidullin, I.S.; Kolesov, S.V. Modification of hyaluronic acid and chitosan, aimed at developing hydrogels for ophthalmology. Russ. J. Appl. Chem. 2014, 87, 1547-1557. [CrossRef]

33. De Oliveira Fulgêncio, G.; Viana, F.A.B.; Silva, R.O.S.; Lobato, F.C.F.; Ribeiro, R.R.; Fanca, J.R.; Byrro, R.M.D.; Faraco, A.A.G.; da Silva Cunha-Júnior, A. Mucoadhesive chitosan films as a potential ocular delivery system for ofloxacin: Preliminary in vitro studies. Vet. Ophthalmol. 2014, 17, 150-155. [CrossRef] [PubMed]

34. Zhu, X.; Xu, D.; Zhu, X.; Li, L.; Li, H.; Guo, F.; Chen, X.; Tan, Y.; Xie, L. Evaluation of chitosan/aptamer targeting TGF- $\beta$ receptor II thermo-sensitive gel for scarring in rat glaucoma filtration surgery. Investig. Ophthalmol. Vis. Sci. 2015, 56, 5465-5476. [CrossRef] [PubMed]

35. Avcu, E.; Baştan, F.E.; Abdullah, H.Z.; Rehman, M.A.U.; Avcu, Y.Y.; Boccaccini, A.R. Electrophoretic deposition of chitosan-based composite coatings for biomedical applications: A review. Prog. Mater. Sci. 2019, 103, 69-108. [CrossRef]

36. Neto, A.I.; Cibrão, A.C.; Correia, C.R.; Carvalho, R.R.; Luz, G.M.; Ferrer, G.G.; Botelho, G.; Picart, C.; Alves, N.M.; Mano, J.F. Nanostructured polymeric coatings based on chitosan and dopamine-modified hyaluronic acid for biomedical applications. Small 2014, 10, 2459-2469. [CrossRef]

37. Tang, J.; Liu, Y.; Zhu, B.; Su, Y.; Zhu, X. Preparation of paclitaxel/chitosan co-assembled core-shell nanofibers for drug-eluting stent. Appl. Surf. Sci. 2017, 393, 299-308. [CrossRef]

38. Tian, D.; Dubois, P.; Jérôme, R. Biodegradable and biocompatible inorganic-organic hybrid materials. I. Synthesis and characterization. J. Polym. Sci. Part A Polym. Chem. 1997, 35, 2295-2309. [CrossRef]

39. Valliant, E.M.; Jones, J.R. Softening bioactive glass for bone regeneration: Sol-gel hybrid materials. Soft Matter 2011, 7, 5083-5095. [CrossRef]

40. Sachot, N.; Castaño, O.; Mateos-Timoneda, M.A.; Engel, E.; Planell, J.A. Hierarchically engineered fibrous scaffolds for bone regeneration. J. R. Soc. Interface 2013, 10, 2-6. [CrossRef] 
41. Mahony, O.; Tsigkou, O.; Ionescu, C.; Minelli, C.; Ling, L.; Hanly, R.; Smith, M.E.; Stevens, M.M.; Jones, J.R. Silica-gelatin hybrids with tailorable degradation and mechanical properties for tissue regeneration. Adv. Funct. Mater. 2010, 20, 3835-3845. [CrossRef]

42. Shirosaki, Y.; Tsuru, K.; Hayakawa, S.; Osaka, A.; Lopes, M.A.; Santos, J.D.; Fernandes, M.H. In vitro cytocompatibility of MG63 cells on chitosan-organosiloxane hybrid membranes. Biomaterials 2005, 26, 485-493. [CrossRef] [PubMed]

43. Wang, D.; Romer, F.; Connell, L.; Walter, C.; Saiz, E.; Yue, S.; Lee, P.D.; McPhail, D.S.; Hanna, J.V.; Jones, J.R. Highly flexible silica/chitosan hybrid scaffolds with oriented pores for tissue regeneration. J. Mater. Chem. B 2015, 3, 7560-7576. [CrossRef] [PubMed]

44. Shirosaki, Y.; Okamoto, K.; Hayakawa, S.; Osaka, A.; Asano, T. Preparation of porous chitosan-siloxane hybrids coated with hydroxyapatite particles. Biomed Res. Int. 2015, 2015. [CrossRef] [PubMed]

45. Connell, L.S.; Romer, F.; Suárez, M.; Valliant, E.M.; Zhang, Z.; Lee, P.D.; Smith, M.E.; Hanna, J.V.; Jones, J.R. Chemical characterisation and fabrication of chitosan-silica hybrid scaffolds with 3-glycidoxypropyl trimethoxysilane. J. Mater. Chem. B 2014, 2, 668-680. [CrossRef]

46. Palla-Rubio, B.; Araújo-Gomes, N.; Fernández-Gutiérrez, M.; Rojo, L.; Suay, J.; Gurruchaga, M.; Goñi, I. Synthesis and characterization of silica-chitosan hybrid materials as antibacterial coatings for titanium implants. Carbohydr. Polym. 2019, 203, 331-341. [CrossRef]

47. Jun, S.H.; Lee, E.J.; Yook, S.W.; Kim, H.E.; Kim, H.W.; Koh, Y.H. A bioactive coating of a silica xerogel/chitosan hybrid on titanium by a room temperature sol-gel process. Acta Biomater. 2010, 6, 302-307. [CrossRef]

48. Malina, D.; Sobczak-Kupiec, A.; Wzorek, Z.; Kowalski, Z. Silver nanoparticles synthesis with different concentrations of Polyvinylpyrrolidone. Dig. J. Nanomater. Biostructures 2012, 7, 1527-1534.

49. Zahra, Q.; Fraz, A.; Anwar, A.; Awais, M.; Abbas, M. A mini review on the synthesis of Ag-nanoparticles by chemical reduction method and their biomedical applications. NUST J. Eng. Sci. 2016, 9, 1-7.

50. Gakiya-teruya, M.; Palomino-marcelo, L.; Rodriguez-reyes, J.C.F. Synthesis of highly concentrated suspensions of silver nanoparticles by two versions of the chemical reduction method. Methods Protoc. 2019, 2, 3. [CrossRef]

51. Brinker, C.J.; Frye, G.C.; Hurd, A.J.; Ashley, C.S. Fundamentals of sol-gel dip coating. Thin Solid Film. 1991, 201, 97-108. [CrossRef]

52. Prochazkova, S.; Vårum, K.M.; Ostgaard, K. Quantitative determination of chitosans by ninhydrin. Carbohydr. Polym. 1999, 38, 115-122. [CrossRef]

53. Shirosaki, Y.; Tsuru, K.; Hayakawa, S.; Osaka, A.; Lopes, M.A.; Santos, J.D.; Costa, M.A.; Fernandes, M.H. Physical, chemical and in vitro biological profile of chitosan hybrid membrane as a function of organosiloxane concentration. Acta Biomater. 2009, 5, 346-355. [CrossRef] [PubMed]

54. ASTM D3359-17 Standard Test Methods for Rating Adhesion by Tape Test; ASTM International: West Conshohocken, PA, USA, 2017.

55. Piveteau, L.D.; Gasser, B.; Schlapbach, L. Evaluating mechanical adhesion of sol-gel titanium dioxide coatings containing calcium phosphate for metal implant application. Biomaterials 2000, 21, 2193-2201. [CrossRef]

56. Haas, K.-H. Hybrid inorganic-organic polymers based on organically modified Si-alkoxides. Adv. Eng. Mater. 2000, 2, 571-582. [CrossRef]

57. Tonda-Turo, C.; Cipriani, E.; Gnavi, S.; Chiono, V.; Mattu, C.; Gentile, P.; Perroteau, I.; Zanetti, M.; Ciardelli, G. Crosslinked gelatin nanofibres: Preparation, characterisation and in vitro studies using glial-like cells. Mater. Sci. Eng. C 2013, 33, 2723-2735. [CrossRef] [PubMed]

58. Serra, A.; Ramis, X.; Fernández-Francos, X. Epoxy sol-gel hybrid thermosets. Coatings 2016, 6, 8. [CrossRef]

59. Zolkov, C.; Avnir, D.; Armon, R. Tissue-derived cell growth on hybrid sol-gel films. J. Mater. Chem. 2004, 14, 2200-2205. [CrossRef]

60. Spirk, S.; Findenig, G.; Doliska, A.; Reichel, V.E.; Swanson, N.L.; Kargl, R.; Ribitsch, V.; Stana-Kleinschek, K. Chitosan-silane sol-gel hybrid thin films with controllable layer thickness and morphology. Carbohydr. Polym. 2013, 93, 285-290. [CrossRef]

61. Catauro, M.; Papale, F.; Bollino, F. Characterization and biological properties of $\mathrm{TiO}_{2} / \mathrm{PCL}$ hybrid layers prepared via sol-gel dip coating for surface modification of titanium implants. J. Non. Cryst. Solids 2015, 415, 9-15. [CrossRef] 
62. Feller, L.; Jadwat, Y.; Khammissa, R.A.G.; Meyerov, R.; Schechter, I.; Lemmer, J. Cellular responses evoked by different surface characteristics of intraosseous titanium implants. BioMed Res. Int. 2015, 2015, 171945. [CrossRef]

63. Tan, G.; Tan, Y.; Ni, G.; Lan, G. Controlled oxidative nanopatterning of microrough titanium surfaces for improving osteogenic activity. J. Mater. Sci. Mater. Med. 2014, 25, 1875-1884. [CrossRef] [PubMed]

64. Schwartz, Z.; Boyan, B.D. Underlying Mechanisms at the Bone-Biomaterial Interface. J. Cell. Biochem. 1994, 56, 340-347. [CrossRef] [PubMed]

65. Liu, D.M.; Chou, H.M.; Wu, J.D. Plasma-sprayed hydroxyapatite coating: Effect of different calcium phosphate ceramics. J. Mater. Sci. Mater. Med. 1994, 5, 147-153. [CrossRef]

66. Wu, V.M.; Uskoković, V. Is there a relationship between solubility and resorbability of different calcium phosphate phases in vitro ? Biochim. Biophys. Acta Gen. Subj. 2016, 1860, 2157-2168. [CrossRef]

67. Usinskas, P.; Stankeviciute, Z.; Beganskiene, A.; Kareiva, A. Sol-gel derived porous and hydrophilic calcium hydroxyapatite coating on modified titanium substrate. Surf. Coat. Technol. 2016, 307, 935-940. [CrossRef]

68. Yang, Y.; Chang, E. Measurements of residual stresses in plasma-sprayed hydroxyapatite coatings on titanium alloy. Surf. Coat. Technol. 2005, 190, 122-131. [CrossRef]

69. Rupp, F.; Gittens, R.A.; Scheideler, L.; Marmur, A.; Boyan, B.D.; Schwartz, Z.; Geis-Gerstorfer, J. A review on the wettability of dental implant surfaces I: Theoretical and experimental aspects. Acta Biomater. 2014, 10, 2894-2906. [CrossRef]

70. Dowling, D.P.; Miller, I.S.; Ardhaoui, M.; Gallagher, W.M. Effect of surface wettability and topography on the adhesion of osteosarcoma cells on plasma-modified polystyrene. J. Biomater. Appl. 2011, 26, 327-347. [CrossRef]

71. Hou, N.; Perinpanayagam, H.; Mozumder, M.; Zhu, J. Novel development of biocompatible coatings for bone implants. Coatings 2015, 5, 737-757. [CrossRef]

72. Wenzel, R.N. Resistance of solid surfaces to wetting by water. Ind. Eng. Chem. 1936, 28, 988-994. [CrossRef]

73. Sundfeldt, M.; Carlsson, L.V.; Johansson, C.B.; Thomsen, P.; Gretzer, C. Aseptic loosening, not only a question of wear: A review of different theories. Acta Orthop. 2006, 77, 177-197. [CrossRef] [PubMed]

74. Banaszkiewicz, P.A. Periprosthetic bone loss in total hip arthroplasty: Polyethylene wear debris and the concept of the effective joint space. Class. Pap. Orthop. 2014, 74, 85-87. [CrossRef]

75. Bhattacharya, P.; Neogi, S. Techniques for deposition of coatings with enhanced adhesion to bio-implants. In Adhesion in Pharmaceutical, Biomedical, and Dental Fields; Mittal, K.L., Etzler, F.M., Eds.; Scrivener Publishing LLC: Beverly, MA, USA, 2017; pp. 235-254. ISBN 9781119323716.

76. Chen, J.; Bull, S.J. Approaches to investigate delamination and interfacial toughness in coated systems: An overview. J. Phys. D Appl. Phys. 2011, 44, 034001. [CrossRef]

77. van Dam, J.P.B.; Abrahami, S.T.; Yilmaz, A.; Gonzalez-Garcia, Y.; Terryn, H.; Mol, J.M.C. Effect of surface roughness and chemistry on the adhesion and durability of a steel-epoxy adhesive interface. Int. J. Adhes. Adhes. 2020, 96, 102450. [CrossRef]

78. He, Y.; Zhang, X.; Hooton, R.D.; Zhang, X. Effects of interface roughness and interface adhesion on new-to-old concrete bonding. Constr. Build. Mater. 2017, 151, 582-590. [CrossRef]

79. Geminger, T.; Jarka, S. Injection molding of multimaterial systems. In Specialized Injection Molding Techniques; Heim, H.-P., Ed.; William Andrew Publishing: Waltham, MA, USA, 2016; pp. 165-210. ISBN 9780323371216.

80. Brown, S.R.; Turner, I.G.; Reiter, H. Residual stress measurement in thermal sprayed hydroxyapatite coatings. J. Mater. Sci. Mater. Med. 1994, 5, 756-759. [CrossRef]

81. Yang, Y.C.; Chang, E. Influence of residual stress on bonding strength and fracture of plasma-sprayed hydroxyapatite coatings on Ti-6Al-4V substrate. Biomaterials 2001, 22, 1827-1836. [CrossRef]

82. Zhang, Z.; Dunn, M.F.; Xiao, T.D.; Tomsia, A.P.; Saiz, E.M. Nanostructured hydroxyapatite coatings for improved adhesion and corrosion resistance for medical implants. Online Proc. Libr. Arch. 2001, 703. [CrossRef]

83. Shockman, G.D.; Barren, J.F. Structure, function, and assembly of cell walls of gram-positive bacteria. Annu. Rev. Microbiol. 1983, 37, 501-527. [CrossRef]

84. Gholizadeh, P.; Ghotaslou, R. The in vitro effects of silver nanoparticles on bacterial biofilms. J. Microbiol. Biotechnol. Food Sci. 2017, 6, 1077-1080. [CrossRef] 
85. Flores, C.Y.; Min, A.G.; Grillo, C.A.; Salvarezza, R.C.; Vericat, C.; Schilardi, P.L. Citrate-capped silver nanoparticles showing good bactericidal e ff ect against both planktonic and sessile bacteria and a low cytotoxicity to osteoblastic cells. ACS Appl. Mater. Interfaces 2013, 5, 3149-3159. [CrossRef] [PubMed]

86. Hwang, E.T.; Lee, J.H.; Chae, Y.J.; Kim, Y.S.; Kim, B.C.; Sang, B.I.; Gu, M.B. Analysis of the toxic mode of action of silver nanoparticles using stress-specific bioluminescent bacteria. Small 2008, 4, 746-750. [CrossRef] [PubMed]

87. Hosseinnejad, M.; Jafari, S.M. Evaluation of different factors affecting antimicrobial properties of chitosan. Int. J. Biol. Macromol. 2016, 85, 467-475. [CrossRef] [PubMed]

88. Flemming, H.C.; Neu, T.R.; Wozniak, D.J. The EPS matrix: The “house of biofilm cells". J. Bacteriol. 2007, 189, 7945-7947. [CrossRef]

89. Díaz, C.; Schilardi, P.; De Mele, M.F.L. Influence of surface sub-micropattern on the adhesion of pioneer bacteria on metals. Artif. Organs 2008, 32, 292-298. [CrossRef] [PubMed]

90. Kumar, P.; Senthamilselvi, S.; Lakshmipraba, A.; Premkumar, K.; Muthukumaran, R.; Visvanathan, P.; Ganeshkumar, R.S.; Govindaraju, M. Efficacy of bio-synthesized silver nanoparticles using Acanthophora spicifera to encumber biofilm formation. Dig. J. Nanomater. Biostructures 2012, 7, 511-522.

(C) 2020 by the authors. Licensee MDPI, Basel, Switzerland. This article is an open access article distributed under the terms and conditions of the Creative Commons Attribution (CC BY) license (http://creativecommons.org/licenses/by/4.0/). 